\title{
Tingkat Kepuasan Pengguna Terhadap Layanan Perpustakan Kota Lubuk Linggau
}

\author{
Hardi Mulyono, Yulpa Rabeta, Endri Mike Setiawan \\ Program Studi Manajemen, Universitas Bina Insan, Lubuklinggau, Indonesia \\ Email: hardi_mulyono@univbinainsan.ac.id,2yulpa_rabeta@univbinainsan.ac.id
}

\begin{abstract}
Abstrak-Penelitian ini bertujuan untuk mengetahui Tinkat Kepuasan Pengguna Terhadap Layanan Perpustakan Kota LubukLinggau. Jumlah sampel penelitian adalah 159 orang. Data diambil dari responden langsung dengan menggunakan instrumen kuesioner. Data analisis menggunakan data analisis kuantitatif, adapun teknik analisis data yang digunakan dalam penelitian ini adalah Uji validitas, Metode Libqual. Pengeolahan data dengan menggunakan aplikasi SPSS 22. Hasil penelitian ini memberikan kesimpulan sebagai berikut (a) hasil penelitian menunjukan bahwa Pelatihan secara parsial mempunyai pengaruh terhadap Kinerja Pegawai. (b) hasil penelitian menunjukan bahwa Kompetensi secara parsial mempunyai pengaruh terhadap Kinerja Pegawai. (c) hasil penelitian menunjukan bahwa terdapat pengaruh yang segnifikan secara simultan antara Pelatihan dan Kompetensi Terhadap Kinerja Pegawai di Kementerian ATR/BPN Kantor Pertanahan Musi Rawas.
\end{abstract}

Kata Kunci: Pelatihan; Kompetensi; Kinerja Pegawai

Abstract-This study aims to determine the effect of training and competence on employee performance in the Ministry of ART / BPN, Musi Rawas Land Office. The number of research samples was 31 people. Data taken from direct respondents using a questionnaire instrument. Data analysis using quantitative data analysis, while the data analysis techniques used in this study are: simple linear regression, multiple linear regression. Processing data using the SPSS 22 application. The results of this study provide the following conclusions: (a) the results of the study show that training has a partial effect on employee performance. (b) the results of the study show that competence partially has an influence on employee performance. (c) the research results show that there is a significant effect simultaneously between Training and Competence on Employee Performance at the Ministry of ATR / BPN, Musi Rawas Land Office.

Keywords: Training; Competence; Employee Performance

\section{PENDAHULUAN}

Perpustakaan merupakan organisasi non-komersil pada bidang jasa yang fokus utamanya pelayanan dan berorientasi kepada kepuasan pengguna. Perpustkaan harus melakukan penilaian dalam hal untuk mengetahui, mengidentifikasi, megukur, menggambarkan, dan menganalisis bagaimana tingkat kepuasan pengguna terhadap kualitas yang telah diberikan oleh perpustakaan selama ini.

Semula penilaian kualitas layanan dinilai dari sudut pandang kelembagan, namun dalam perkembangannya kualitas layanan dinilai dari sudut pandang pengguna (Studi, Perpustakaan, Ilmu, Budaya, \& Indonesia, n.d.).

Dalam memberikan pelayanan kepada para pengunjung, perpustakaan Kota Lubuklinggau memiliki komitmen untuk memberikan pelayanan yang unggul atau disebut juga dengan service excellence, yakni suatu sikap atau cara dalam melayani pelanggan secara memuaskan(Endang Fatmawati, Sos, \& Nugroho, 2012). Akan tetapi, perpustakaan Kota Lubukinggau masih memiliki kekurangan yaitu kurang lengkapnya data elektronik sehingga membuat para pengunjung kesulitan dalam mencari data dan petugas perpustakaan yang kurang tanggap dalam melayani pengunjung. Padahal seharusnya sebagai pusat rujukan informasi, seharusnya perpustakaan memberikan pelayanan yang berkualitas. Untuk itu diperlukan sebuah metode untuk mengukur kualitas layanan sistem perpustakaan. Metode pengukuran terhadap kualitas layanan perpustakaan dapat memberikan gambaran serta memberikan masukan dalam memprediksi dan memperbaiki suatu layanan tertentu dalam pencapaian kualitas layanan yang lebih baik. Metode yang dimaksud adalah metode atau sistem yang sesuai dengan standar baku pelayanan publik yaitu Libqual+TM.

Banyak penelitian mengenai pengukuran jasa layanan perpustakaan yang menempatkan tanggapan pemustaka sebagai bagian dari penelitian evaluasi kinerja perpustakaan secara keseluruhan. Diantaranya penelitian yang di tulis oleh (Nurvia \& Anggraini, 2016) yang berjudul Pengukuran kualitas layanan digital library terhadap kepuasan pengguna menggunakan metode Libqual $+T M$.

Salah satu metode yang khusus (28) dikembangkan untuk mengukur kualitas layanan perpustakaan adalah Libqual $+T M$ (Library Quality). Metode Libqual $+T M$ adalah pengembangan dari Servqual yang digunakan untuk mengukur tingkat kepuasan pemustaka terhadap kualitas pelayanan perpustakaan(Prastiya, 2016).

Seperti halnya dalam dimensi service affect, pustakawan wajib mengetahui kebutuhan pengguna, dimensi personal control pustakawan memberikan petunjuk yang jelas tentang apa yang dibutuhkan oleh pengguna, dalam dimensi library as place perpustakaan wajib memberikan ruangan yang nyaman bagi pengguna agar pengguna terasa nyaman dan aman, dan dalam dimensi information access perpustakaan mempunyai koleksi buku yang lengkap untuk pengguna.

\section{KERANGKA TEORI}

\subsection{Perpustakaan Umum}


Perpustakaan berasal dari kata pustaka yang berarti kitab; buku, sedangkan arti perpustakaan itu sendiri adalah(Zaharani \& Primadesi, 2014):

a. Tempat, gedung, ruang yang disediakan untuk pemeliharaan dan penggunaan koleksi buku dan sebagainya.

b. Koleksi buku, majalah, dan bahan pustaka lainnya yang disimpan untuk dibaca, dipelajari, dibicarakan.

Perpustakaan umum adalah perpustakaan yang melayani seluruh lapisan masyarakat tanpa membedakan latar belakang, status sosial, agama, suku, pendidikan, dan sebagainya. Konsep dasar dari perpustakaan umum adalah didirikan oleh masyarakat, untuk masyarakat dan dengan dana masyarakat. Namun demikian dalam banyak hal, perpustakaan umum banyak yang dilaksanakan oleh pemerintah(Hermawan, 2006).

Perpustakaan umum memiliki tugas pokok, yaitu menyediakan, mengelola memelihara dan mendayagunakan koleksi bahan pustakamenyediakan sarana pemanfaatannya dan melayani masyarakat pengguna yang membutuhkan informasi dan bahan bacaan(RI, 2000). Jenis pelayanan dilingkungan perpustakan umum, yaitu(Yusuf, 2016):

a. Pelayanan sirkulasi

Layanan sirkulasi adalah peredaran atau keluar- masuknya bahan pustaka. Untuk kelancaran pelayanan maka digunakan sistem tertentu agar ada tanggung jawab pemakai terhadap jasa layanan perpustakaan, seperti adanya tata tertib dalam peminjaman bahan pustaka (sanksi jika telat dalam pengembalian).

b. Pelayanan referensi

Pelayanan referensi di perpustakaan umum sangat berperan untuk memenuhi kebutuhan pendidikan, penelitian, rujukan, dan informasi lokal seperti peraturan daerah, dokumentasi pemerintah dan sebagainya. Buku referensi tersebut tidak diperkenankan untuk dipinjam.

c. Pelayanan ekstansi

Pelayanan ekstansi dilakukan untuk menjangkau pemukiman masyarakat yang terpencil atau jauh dari Perpustakaan Umum, dengan menyediakan koleksi yang sesuai dengan kondisi kegiatan masyarakat yang terlayani.

d. Bimbingan pembaca

Bimbingan pemakai jasa perpustakaan mempunyai pengertian sebagai bantuan yang diberikan oleh pustakawan atau petugas khusus dari Perpustakaan Umum untuk mengarahkan pemakai jasa perpustakaan, agar tidak terjadi pelanggaran peraturan yang berlaku di perpustakaan.

e. Kerjasama perpustakaan umum

Kerjasama perpustakaan untuk mengindari duplikasi materi yang tidak diinginkan dan memperluasjenis materi yang tersedia dengan memanfaatkan anggaran yang ada dari tiap perpustakaan agar lebih efisien.

Kepuasan pemustaka adalah tingkat perasaan seseorang setelah membandingkan kinerja (atau hasil) yang ia rasakan dibandingkan dengan harapannya. Kepuasan adalah keseluruhan sikap yang ditunjukan pengguna atas suatu produk (barang atau jasa) setelah mereka memperoleh dan menggunakannya(Metode, Tm, Ilyas, \& Nurislaminingsih, n.d.).

Layanan yang baik adalah layanan yang dapat memberikan rasa senang dan puas kepada pemakai. Baik buruknya citra perpustakaan juga ditentukan bagian ini. Oleh karena itu, setiap perpustakaan selalu berupaya penuh guna memuaskan pemakai perpustakaan tersebut. Layanan perpustakaan adalah Suatu layanan yang menawarkan semua bentuk koleksi yang dimiliki oleh perpustakaan kepada yang datang ke perpustakaan yaitu pemakai dan meminta informasi yang dibutuhkan pemakai".

Dengan kata lain tujuan layanan perpustakaan adalah cara untukmempertemukan pembaca (pemustaka) dengan bahan pustaka yang mereka minati dan membantu memenuhi kebutuhan dan tuntutan masyarakat tentang informasi yang sesuaidengan kebutuhan. Jadi hakikat layanan perpustakaan adalah penyediaan segala bentuk informasi kepada pemakai dan penyediaan segala alat bantu penelusurannya(Rakib 2016).

\subsection{Metode Libqual+TM+TM}

Metode Libqual $+T M^{+T M}$ digunakan untuk mengukur kualitas layanan perpustakaan berdasarkan persepsi dan harapan pemustaka. Kualitas layanan perpustakaan diukur di antaranya dengan menggunakan model analisis kesenjangan (gap analysis model). Model analisis kesenjangan (gap analysis model) merupakan nama lain dari model SERVQUALyang saat ini telah diadaptasi oleh metode Libqual $+T M^{+T M}$ (Metode et al., n.d.).

Libqual $+T M^{+T M}$ dalam metode pengukurannya menggunakan empat dimensi. Adapun keempat dimensi tersebut adalah sebagai berikut(Nurvia \& Anggraini, 2016):

a. Kemampuan dan sikap pustakawan dalam melayani (Affect Of Service-AS) yaitu, kemampuan, sikap dan mentalitas pustakawan dalam melayani pemustaka.

b. Fasilitas dan suasana ruang perpustakaan (Library As Place). Dimensi ini menjelaskan bahwa perpustakaan dianggap sebagai sebuah tempat yang mempunyai kemampuan untuk menampilkan sesuatu secara nyata berupa fasilitas fisik (Physical Facilities), bagaimana perpustakaan dalam memanfaatkan ruang, peralatan/perabotan (Equipment), ketersediaan sarana peralatan komunikasi dan petugas, maupun sebagai simbol dan tempat perlindungan.

c. Petunjuk dan sarana akses (Personal Control), yaitu konsep yang membuat pemustaka dapat melakukan sendiri apa yang diinginkannya dalam mencari informasi tanpa bantuan pustakawan.

d. Akses informasi (Information Acces), yaitu menyangkut ketersedian bahan perpustakaan yang memadai, kekuatan koleksi/bahan pustaka yang dimiliki, cakupan isi/ruang lingkup (Content/Scope), aktualitas, bimbingan pustakawan, maupun tingkat kecepatan waktu akses informasi di perpustakaan (Timelines). 


\subsection{Penelitian Terdahulu}

a. Penelitian pada tahun 2014 yang berjudul "Pengaruh Layanan Perpustakaan Terhadap Kepuasaan Pemustaka di Perpustakaan Universitas Negeri Padang”(Zaharani \& Primadesi, 2014)

b. Penelitian pada tahun 2016 yang berjudul "Pengukuran Kualitas Layanan Digital Library Terhadap Kepuasan Pengguna Menggunakan Metode Libqual+TM(Studi Kasus : Perpustakaan Badan Pusat Statistik Provinsi Riau)(Nurvia \& Anggraini, 2016)

c. Penelitian pada tahun 2016 yang berjudul "Analisis Tingkat Kepuasan Pemustaka Terhadap Layanan Perpustakaan Dengan Menggunakan Metode Libqual+TM (Studi Kasus : Stmik Budi Darma Medan) (Prastiya, 2016).

\subsection{Kerangka Berpikir dan Hipotesis}

Berikut merupakan kerangka berpikir dalam pelaksanaan penelitian

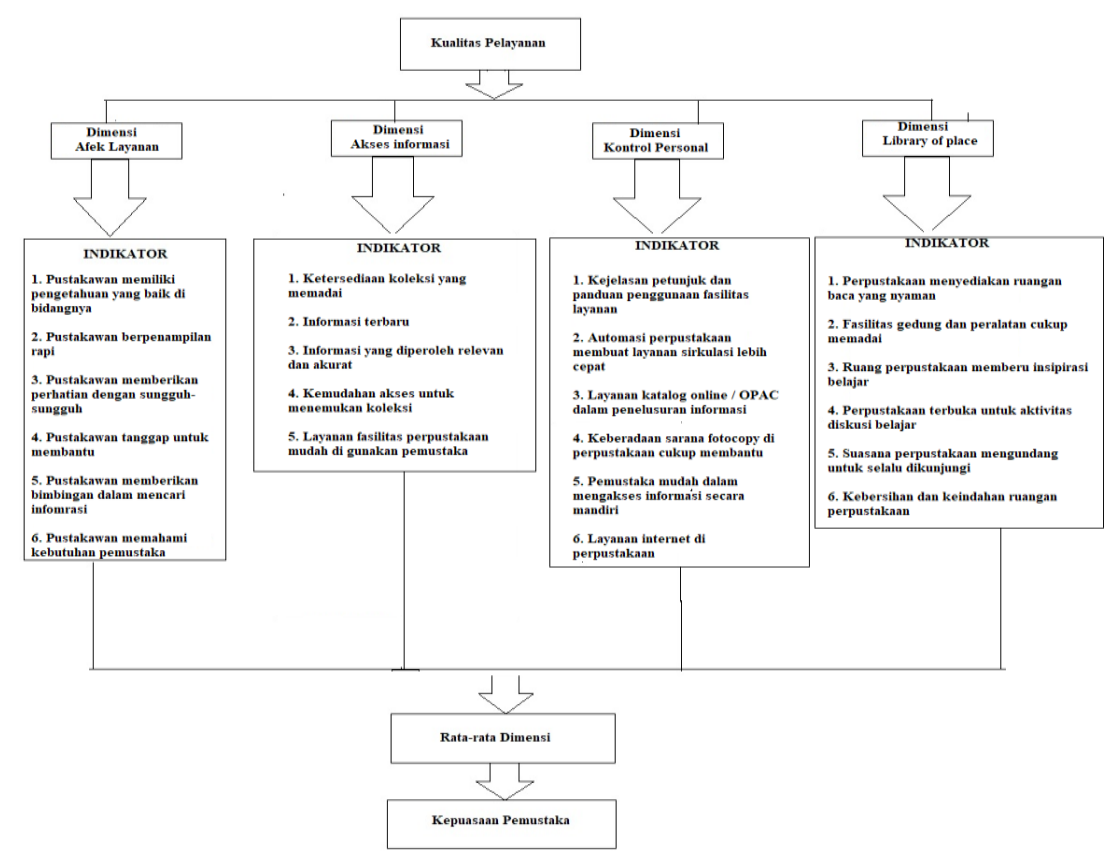

Berikut merupakan hipotesis

Gambar 1. Kerangka berpikir

1) $\mathrm{AG}($ Adequacy Gap) = Persepsi (P) - Harapan Minimum (HM) AG (Adequacy Gap) merupakan nilai selisih yang diperoleh dari persepsi (P) dikurangi dengan harapan minimum (HM). Jadi AG akan bernilai positif, yang berartiresponden "cukup puas" adalah apabila jika persepsi $>$ harapan minimum (P $>$ HM).

2) SG (Superiority Gap) = Persepsi (P) - Harapan Ideal (HI) SG (Superiority Gap) merupakan nilai selisih yang diperoleh dari persepsi (P) dikurangi dengan harapan ideal (HI). Nilai SG akan negatif, yang berarti "dalam batas toleransi (zone of tolerance)" adalah jika persepsi $<$ harapan ideal $(\mathrm{P}<\mathrm{HI})$.

3) Zone of Tolerance, merupakan suatu wilayah (area) antara tingkat minimum (HM) yang bisa diterima dan tingkat harapan ideal (HI).

\section{METODE PENELITIAN}

\subsection{Desain Penelitian}

Penelitian ini menggunakan metode penelitian kuantitatif dengan desain penelitian deskriptif. Subjek dalam penelitian ini adalah pemustaka di perpustakaan Kota Lubuklinggau yang memanfaatkan layanan perpustakaan. Sementara itu, objek penelitian ini adalah kualitas layanan perpustakaan Kota Lubuklinggau. Peneliti menentukan informan dalam penelitian ini dengan menggunakan teknik slovin. Persamaan teknik slovin sebagai berikut (Rahmawati \& Bachtiar, 2018) :

$$
\begin{aligned}
& n=N(1+N e 2) \\
& \text { Keterangan } \\
& \mathrm{n}=\text { Jumlah sampel } \\
& \mathrm{N}=\text { Jumlah Seluruh Populasi } \\
& \mathrm{E}=\text { Toleransi Error }
\end{aligned}
$$




\subsection{Populasi dan Sampel}

a. Populasi

Pada penelitian ini yang menjadi populasi penelitian adalah anggota tetap perpustakaan selaku pemustaka di perpustakaan Kota Lubuklinggau sebanyak 265 member.

b. Sampel

Untuk menentukan jumlah sampel dari populasi sebanyak 265 member, peneliti akan menggunakan rumus slovin (1).

$$
\begin{aligned}
& \mathrm{n}=265 / 1+\mathrm{Ne}^{2} \\
& \mathrm{n}=265 / 1+265(0,05)^{2} \\
& \mathrm{n}=265 / 1+(265 \times 0,0025) \\
& \mathrm{n}=265 / 1+(0,6625) \\
& \mathrm{n}=265 / 1,6625 \\
& \mathrm{n}=159,398 \\
& \mathrm{n}=159
\end{aligned}
$$

Jadi untuk sampel yang dipakai berdasarkan teknik slovin adalah sebanyak 159 member. Dari 159 member yang didapatkan, selanjutnya penulis melakukan teknik random sampling agar kuisioner dapat diisi dari member tersebut.

\subsection{Teknik Analisis data}

Analisi data kepuasan pemustaka terhadap kualitas layanan menggunakan Metode Libqual $+T M++T M$ yang dilakukan dalam tahap-tahap sebagai berikut (Metode et al., n.d.).

a. Menghitung total penilaian ketegori harapan minimum, total penilaian kategori harapan ideal (desired) dan total penilaian kategori persepsi yang telah dijabarkan dalam setiap item pernyataan.

b. Menghitung rata-rata dari keseluruhan nilai pada kategori harapan minimum, harapan ideal dan total penilaian kategori persepsi.

c. Kemudian skor rata-rata setiap pernyataan dalam suatu dimensi dijumlahkan kemudian dibagi dengan frekuensi pernyataan tiap dimensi untuk mengetahui rata-rata nilai masing-masing dimensi.

d. Mengukur tingkat kepuasan pemustaka menggunakan metode Libqual $+T M++T M$ dengan cara menghitung nilai kesenjangan (Gap) dari kategori harapan minimum, kategori harapanideal dan kategori persepsi.

\section{HASIL DAN PEMBAHASAN}

Analisis hasil penelitian akan membahas terkait variabel-variabel yang dijadikan indikator dalam kuisioner penelitian. Adapun variabel tersebut meliputi Afek Layanan yang terdiri dari 6 pernyataan, Akses Informasi yang terdiri dari 5 pernyataan, Kontrol Personal yang terdiri dari 6 pernyataan dan Library of Place yang terdiri dari 6 pernyataan. Dari analisis ini maka nantinya akan mendapatkan nilai GAP antara layanan yang diharapkan dengan kinerja yang diterima. Tahapan yang dilakukan diantaranya yaitu:

a. Pengelompokan data mentah yang kemudian diolah kedalam bentuk data libqual $^{+t m}$, pengelompokan ini dibagi menjadi 3 kelompok yaitu nilai rata-rata persepsi, nilai rata-rata harapan minimum, dan nilai rata-rata ideal.

b. Kemudian langkah selanjutnya peneliti menentukan penilaian setiap dimensi dengan cara menjumlahkan semua kuisioner berdasarkan pernyataan yang sama di bagi berdasarkan banyaknya koresponden, dalam hal ini koresponden sebanyak 159.

Hasil dari perhitungan nilai libqual ${ }^{+t m}$ berdasarkan dimensi nya diantaranya yaitu :

1. Dimensi Afek Layanan, idikator perpustakaan memiliki pengetahuan yang baik dibidangnya dengan persepsi (P) 4.05, nilai harapan minimum (HMI) 4.05 dan harapan ideal (HMA) 4.56

2. Dimensi Akses Informasi, idikator Ketersediaan koleksi yang memadai dengan persepsi ( P ) 3.80, nilai harapan minimum 3.86 dan harapan ideal 4.34

3. Dimensi Kontrol Perseonal, idikator kejelasan petunjuk penggunaan fasilitas layanan dengan persepsi 3.80, nilai harapan minimum 3.85 dan nilai harapan ideal 4.34

4. Dimensi Library of place, idikator perpustakaan menyediakan ruangan baca yang nyaman dengan persepsi 3.89, nilai harapan minimum 3.97 dan harapan ideal 4.47.

c. Perhitungan Adequcy Gap ( AG)

AG merupakan nilai selisih yang diperoleh dari persepsi dikurangi dengan harapan minimum. Apabila skor AG menunjukkan nilai yang negatif, maka hal ini menunjukkan bahwa layanan yang diberikan belum memenuhi harapan minimum pemustaka, sehingga pemustaka "belum puas" terhadap layanan yang diterimanya. Jadi bisa dikatakan bahwa layanan yang diberikan di bawah nilai minimum. Nilai AG dapat dilihat dengan persamaan di bawah ini :

$$
A G(\text { Adequacy Gap })=\text { Persepsi - Harapan Minimum }
$$

1. Dimensi Afek Layanan Indikator perpustakaan memiliki pengetahuan yang baik dibidangnya $\mathrm{AG} \quad=$ Persepsi - Harapan Minimum 


$$
\begin{aligned}
& =4.00-4.05 \\
& =-0.05
\end{aligned}
$$

2. Dimensi Akses Informasi, idikator Ketersediaan koleksi yang memadai

$\mathrm{AG}=$ Persepsi - Harapan Minimum

$=3.80-3.86$

$$
=-0.06
$$

3. Dimensi Kontrol Perseonal, idikator kejelasan petunjuk penggunaan fasilitas layanan

$$
\begin{aligned}
& \mathrm{AG}=\text { Persepsi }- \text { Harapan Minimum } \\
& =3.80-3.85
\end{aligned}
$$$$
=-0.05
$$

4. Dimensi Library of place, idikator perpustakaan menyediakan ruangan baca yang nyaman

$$
\begin{aligned}
& \mathrm{AG}=\text { Persepsi - Harapan Minimum } \\
& =3.89 \text { - 3.97 }
\end{aligned}
$$

$$
=-0.08
$$

\section{d. Perhitungan Superiority Gap (SG)}

SG merupakan nilai selisih yang diperoleh dari persepsi dikurangi dengan harapan ideal. Apabila skor SG menunjukkan nilai yang negatif, menunjukkan bahwa kualitas layanan dinilai "baik", berada "dalam batas toleransi/ zone tolerance", dimana kualitas layanan berada di antara tingkat minimum yang dapat diterima dan tingkat harapan ideal(desired).

$$
\text { SG }(\text { Superiority Gap })=\text { Persepsi - Harapan Ideal }
$$

1. Dimensi Afek Layanan Indikator perpustakaan memiliki pengetahuan yang baik dibidangnya

$$
\text { AG = Persepsi }- \text { Harapan Ideal }
$$$$
=4.00-4.56
$$$$
=-0.56
$$

2. Dimensi Akses Informasi, idikator Ketersediaan koleksi yang memadai

AG $=$ Persepsi - Harapan Minimum

$=3.80-4.34$

$=-0.54$

3. Dimensi Kontrol Perseonal, idikator kejelasan petunjuk penggunaan fasilitas layanan

$\mathrm{AG}=$ Persepsi - Harapan Minimum

$=3.80-4.34$

$=-0.54$

4. Dimensi Library of place, idikator perpustakaan menyediakan ruangan baca yang nyaman

$\mathrm{AG}=$ Persepsi - Harapan Minimum

$=3.89-4.47$

$=-0.58$

Analisis hasil keseluruhan nilai harapan minimum, nilai harapan ideal, persepsi, nilai AG dan SG maka bahwa nilai kesejangan antara harapan pemustaka terhadap resepsi di perpustakaan Kota Lubuklinggau masih kurang puas karena nilai Adequcy Gap semuanya masih bernilai negative.

\section{KESIMPULAN}

Hasil penelitian ini yang terdiri dari 256 populasi pemustaka yang ada dan sampel 159 menghasilkan jumlah persetase koresponden pemustakan berdasarkan jenis kelamin, status perkawinan, usia dan tingkat pendidikan. Bahwa dari ke 4 dimensi yang ada yaitu afek layanan, akses informasi, control personal dan library of place menunjukan bahwa nilai AG bernilai negative, maka bisa di Tarik kesimpulan bahwa pelayanan yang diberikan oleh pihak perpustakaan masih belum optimal dikarenakan pemustaka masih kurang puas terhadap pelayanan tentang pustakwan memiliki pengetahuan yang baik dibidangnya.

\section{DAFTAR PUSTAKA}

Endang Fatmawati, S. S., Sos, S., \& Nugroho, I. E. (2012). EVALUASI KUALITAS LAYANAN PERPUSTAKAAN FEB UNDIP DENGAN METODE LibQUAL+ TM. Berkala Ilmu Perpustakaan Dan Informasi, VIII(1), 1-18. https://doi.org/http://dx.doi.org/10.22146/bip.7725

Hermawan, Z. Z. dan R. S. (2006). Etika Kepustakawanan. Jakarta: Sagung Seto.

Metode, B., Tm, L., Ilyas, M., \& Nurislaminingsih, R. (n.d.). Analisis kualitas pelayanan koleksi khusus di perpustakaan nasional republik indonesia berdasarkan metode libqual.

Nurvia, E., \& Anggraini. (2016). PENGUKURAN KUALITAS LAYANAN DIGITAL LIBRARY ( Studi Kasus : Perpustakaan Badan Pusat Statistik Provinsi Riau ). Jurnal Rekayasa Dan Manajemen Sistem Informasi, 2(2), 2016. 
Prastiya, K. (2016). Analisis Tingkat Kepuasan Pemustaka Terhadap Layanan Perpustakaan Dengan Menggunakan Metode Libqual (Studi Kasus: STMIK Budi Darma Medan ). JURIKOM (Jurnal Riset Komputer), 3(6), 70-73.

Rahmawati, N. A., \& Bachtiar, A. C. (2018). Analisis dan perancangan sistem informasi perpustakaan sekolah berdasarkan kebutuhan sistem. Berkala Ilmu Perpustakaan Dan Informasi, 14(1), 76. https://doi.org/10.22146/bip.28943

Rakib, F. A. (2013). Kepuasan Pemustaka Terhadap Layanan Perpustakaan Keliling Terapung (Studi Kasus di Kota Ternate). Ilmu Perpustakaan, II(4), 1-13.

RI, P. N. (2000). Pedoman Umum Penyelenggaraan Perpustakaan Umum. Jakarta.

Studi, P., Perpustakaan, I., Ilmu, F., Budaya, P., \& Indonesia, U. (n.d.). DEPOK Izhaar Dienillah Abstrak User Satisfaction of Public Library Service at Kantor Arsip dan Perpustakaan Pemerintah Kota Depok Abstract.

Yusuf, T. (2016). Manajemen Perpustakaan Umum. Jakarta: Universitas Terbuka.

Zaharani, R., \& Primadesi, Y. (2014). Pengaruh layanan perpustakaan terhadap kepuasan pemustaka di perpustakaan universitas negeri padang. (September), 152-158. 